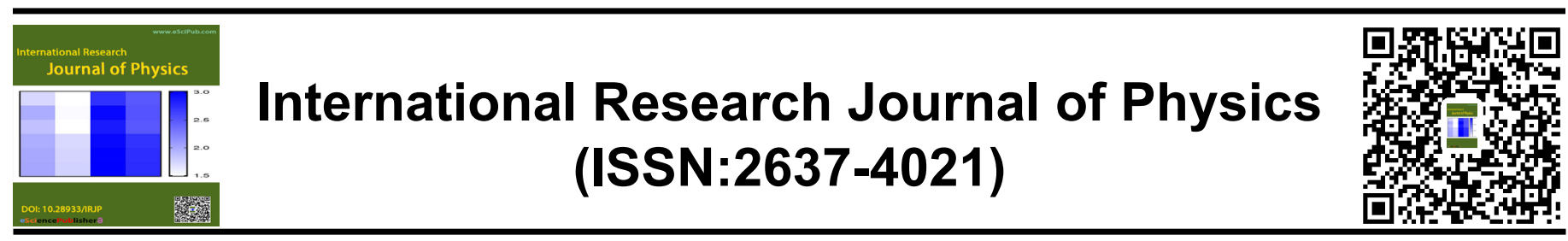

\title{
Subcritical nuclear power and economic development, proposals
}

Florent Pirot

Independent researcher

ABSTRACT

This paper presents different concepts of interest for nuclear power development, in a balanced way, aimed at communities, industrial development, yachting and military purposes. Nuclear power can serve anywhere in the globe. This paper is intended at contributing to making it happen, in the "atoms for peace" spirit.

How to cite this article:

Florent Pirot. Subcritical nuclear

Keywords : community economics, economic development, inpower and economic development, dustrialization, economic growth, reactors of common sense proposals. International Research Journal of Physics, 2021, 4:8.

\section{eScîPub}

eSciPub LLC, Houston, TX USA.

Website: http://escipub.com/ 
1. Urvarukam reproduced as a subcritical nuclear reactor : the zucchini core

Urvarukam (the fruit of knowledge) is intrinsically linked with brain power. Brain power is fed by its consumption. It linearly compensates useful brain work.

Urvarukam may be morphologically translated into a nuclear core, subcritical, with a piston. This instrument will serve for e.g. molten salts (with a mix of $\mathrm{Na}, \mathrm{Be}$, etc) mixed into oil (petroleum), thorium-232 (for instance or depleted uranium) and some plutonium-239 in very light amounts (less plutonium if depleted uranium is used).

This zucchini core is useful for controlled nuclear power in various ways. It is universal for civilian usages and long-lasting when made in rolled homogeneous osmium surrounded by a water loop connected to a hydrowheel generator (the usual set up of a nuclear reactor in other words, but with this subcritical core).

No need to draw a figure. Anyone can take a zucchini and imagine a cylindrical piston surrounded by a cylinder pluging in said zucchini core. However this nuclear core concept is more adapted to flat areas where zucchinis grow.

\section{The solarpowered carrot for communities living near the Equatorian area - Africa especially}

The combination of solar power and nuclear energy allows to cycle more fertile atoms by accelerating neutrons slightly with solar heat entrying on the core.

The fission of fertile atoms will be possible quite easily in this core dedicated to Lakshmi and Shiva.

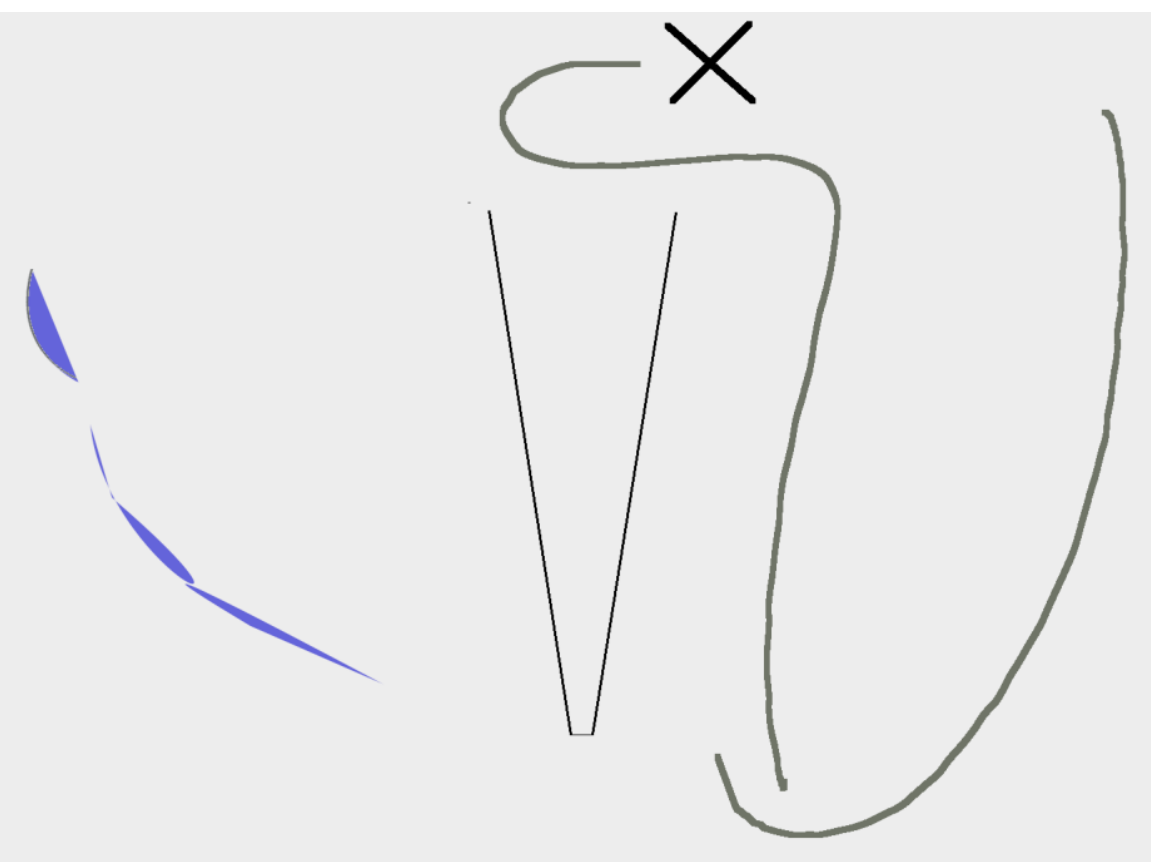

Why is the drawing left so empty ? It benefits from the possibility of actually pumping air instead of using water. The wheel can use local air. Fermionic condensation will not happen in the core. Local soils have to be used. African soils having seen little to no loss of radioactivity since the beginning of times as implicitly demonstrated in [1], these are the most appropriate for this subcritical reactor targeting small communities, self-organized and not countries where the administration is too much messing with small communities. However the small communities will have a responsibility (in 
return for the right to organize this subcritical power without any administrative monitoring) which is to ensure there is someone in their community always watching, holding a rope allowing to pull a non-drawn liberator of the fuel to the bottom. So that it scatters around the core content, helping to kill stealers. This is betterly ensured by also owning some rifles, for instance, to kill definitively those that survived the radioactive shower. The top however is always tightly closed except for the periods of filling.

Contaminated soils are later pelleted, shoveled back in the core for slightly more power and in this particular system it is allowed to shovel in as well bodies of stealers for more moderation, nevertheless reducing the core plutogenization (but if they had RPGs and RPGs are shoveled in as well, this compensates).

See also how Lakshmi and Shiva's dedication is related to the need of having always one arm available for pulling the rope.

Core power decreases naturally during night time, in harmony with typical community lifestyle. It might support electric-powered tractors for local agriculture without animal pulling and contributes hence to overall welfare.

4 meters 70 centimers high is the expected height of the carrot. The walls of the tungstenonly core have to be extremely thin (3 centimeters maximum) to allow maximum transfer of mirror-catalyzed solar energy in the carrot. Several mirror lines can of course be used.

4 meters away from such a carrot core at work trees can grow and strive without any significant radiation damage, which is why areas with intermediate vegetation density, sub-Sahelian are thought of as an ideal buyer of such products ${ }^{1}$.

\section{Combining geothermy and nuclear power}

1 It is reminded how almost impossible the transformation of said low-power core with hot walls into a weapon makes this carrot core possible for the poorest areas on the globe.
This proposal relates to the use of geothermal energy to pressurize a core and increase its yield. City pressure actually delivers some geothermy (as proven for instance under the city of Paris) that can be ducted into this.

The author tends to think that even Plinian eruptions are extremely beautiful but perhaps the common people might think otherwise and want such systems to be deployed around volcanoes massively.

A word of memory. Pompeii and Herculanum were brothel-based city projects. Pompeii for blowjobs, Herculanum for homosexual customers (which is why it seems Italians are so fearful of digging that second one). The wiping out (compare with [2]) was not understood and Barbarians had to eventually finish off the Roman Empire.

\section{Capture of underwater NORMs}

It is possible to adapt a subcritical based on the Triga described in [3] with an underwater hose and capture the NORMs. A guillotine clenched around cuts entry of water while allowing the entry of the NORMs, fission activity in the core allowing simply this rapid capture of the most active alpha emitters.

The user has to be fully responsible of the core's laser power with imperatively a rope he/she pulls to kill laser power. Griding the entry of the hose is imperative to bar fish from getting sucked in.

The incitation this system creates for Ra226/228 contamination in diesel (in particular) creates a moral issue. It nevertheless is suggested for yachting and for dreadnoughts. It is impossible to dedicate it to Ganesh except with some research project at the same time by the owner(s) on the ship powered by it.

\section{Human faeces - powered core}

Any epuration station can replace the open air slow eating by bacteria, and washing, by an

Plutonium extraction cannot be excluded. But the main risk is the displacement as a large dirty bomb of the whole core. Other risks are quasi absent.

IRJP: http://escipub.com/international-research-journal-of-physics/ 
extremely large steel - gadolinium - $90 \%$ lead core controlled by laser pulse, reproducing the concept of [3].

This new-generation epuration station benefits communities by killing all odors, and provides energy. The NORMs in human faeces and urine are the power base.

\section{Conclusion}

It is also interesting to recycle old tanks as energy producers with a tube inserted through the opening left by the shaped charge or the top turret (in which a hole may have to be carved, in the process of recycling non-used tanks in military stockpiles), going out through the cannon, the cannontube directed onto a dynamo for electricity production, after filling with water and locking above (and plugging leftover holes).

This method allows to make use of the depleted uranium contamination in tanks. In this case a fire would have to be lit under the tank to accelerate. Chlorine could be added into the liquid filling of the tank. In both cases the low yield of RPGs, ATGMs... is the main driver of the reaction (with the use of DU shaped charge RPGs / ATGMs in non-used tanks and limited heating under it, or at your own risk). Aluminium is suggested as main component of the tube $(90 \%)$ altogether with some tungsten carbide (10\%, outside). Tanks armoured inside with depleted uranium armour also become an energy source in this pattern except if the DU layer is too external (pouring a layer of molten lead all onto the tank is then enough to use it safely).

\section{References}

[1]. Pirot F, Fermionic Condensation Explains the Formation of Subcontinents and Small Volcanic Islands around Them - General Geophysical Rules. International Journal of Physics. 2021; 9(1):42-47. doi: 10.12691/ijp-9-1-5

[2]. Pirot F, A Rule of Natural Disasters Coming to Rebalance Unjust Development and Irresponsibility-Laws of Physics Explain the Trope of "Divine Retribution" against the "Nouveaux Riches", International Journal of Physics. 2019, 7(4), 135-140. doi: 10.12691/ijp-7-4-4

IRJP: http://escipub.com/international-research-journal-of-physics/
[3]. Pirot F, A TRIGA-like subcritical concept for biological waste management (pills, old vaccines etc.). Research Journal of Pharmacology and Pharmacy, 2021, 5:12. DOI: 10.28933/rjpp-202107-1006

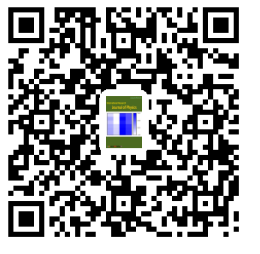

